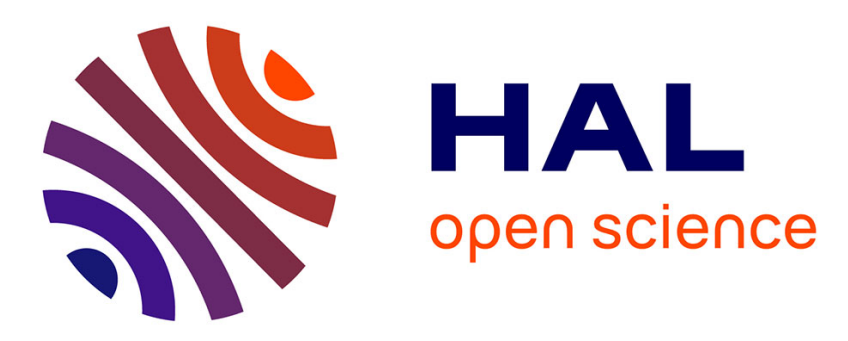

\title{
Wireless Hydrogen Pressure Dosimeter for Nuclear High Dose Monitoring
}

Émilie Debourg, Julien Philippe, Hervé Aubert, Patrick Pons, I Augustyniak, P Knapkiewicz, J Dziuban, M Matusiak, M Olszacki

\section{To cite this version:}

Émilie Debourg, Julien Philippe, Hervé Aubert, Patrick Pons, I Augustyniak, et al.. Wireless Hydrogen Pressure Dosimeter for Nuclear High Dose Monitoring. IEEE Sensors, Oct 2016, Orlando, United States. hal-01396854

\section{HAL Id: hal-01396854 https://hal.science/hal-01396854}

Submitted on 15 Nov 2016

HAL is a multi-disciplinary open access archive for the deposit and dissemination of scientific research documents, whether they are published or not. The documents may come from teaching and research institutions in France or abroad, or from public or private research centers.
L'archive ouverte pluridisciplinaire HAL, est destinée au dépôt et à la diffusion de documents scientifiques de niveau recherche, publiés ou non, émanant des établissements d'enseignement et de recherche français ou étrangers, des laboratoires publics ou privés. 


\section{Wireless Hydrogen Pressure Dosimeter for Nuclear High Dose Monitoring}

\author{
E Debourg, J. Philippe, H. Aubert, P.Pons \\ LAAS-CNRS, Université de Toulouse, CNRS, INP \\ Toulouse, France
}

\author{
I. Augustyniak, P. Knapkiewicz, J. Dziuban \\ Wrocław University of Technology \\ Wrocław, Poland \\ M. Matusiak, M.Olszacki \\ National Centre for Nuclear Research \\ Otwock, Poland
}

\begin{abstract}
This communication reports the very first experimental results on an original wireless, chipless and passive (battery-less) sensor for monitoring high doses of nuclear radiation. The micro-sensor combines a miniature hydrogen pressure dosimeter with a passive microwave resonator. The pressure response is derived from $S_{11}$-parameter measurement using vacuum and atmospheric pressure conditions. After e-beam irradiation $(20 \mathrm{kGy})$ the resonant frequency shift of the resonator ranges between $0.12 \% / \mathrm{kGy}$ and $0.42 \% / \mathrm{kGy}$ while the hydrogen pressure inside the cavity varies from $20 \mathrm{mbar} / \mathrm{kGy}$ to $90 \mathrm{mbar} / \mathrm{kGy}$. No significant frequency shift is observed when using sensors during 6 months. These results demonstrate that a good hydrogen hermetic seal was fabricated during the manufacturing process of the constitutive micro-cavity.
\end{abstract}

Keywords - Hydrogen pressure dosimeter, wireless passive chipless sensor

\section{INTRODUCTION}

The safety of nuclear infrastructures may involve the monitoring of many parameters in harsh environments with high radiation levels, high temperature and high pressure conditions. If technological solutions exist for manufacturing transducers, the electronics of the reader is not appropriate in such extreme environments. Well-known solutions consist of connecting the transducer to the reader by using long cables or by performing ex-situ remote sensing. However cables or wires may be difficult to implement in practice while ex-situ measurements are not applicable for on-line monitoring. Wireless, chipless (without integrated circuit) and passive (battery-less) sensors could be a very convenient solution for the remote sensing of physical parameters in harsh environments. Applying the electromagnetic transduction principle many microwave and millimeter-wave sensors have been manufactured at LAAS-CNRS, such as pressure, temperature and strain sensors, as well as a radar-based solution for the wireless and long-range sensors interrogation (see, e.g., [1-5]). Very recently the authors have proposed a new concept of wireless, chipless and passive dosimeter which overcomes the limitations of state-of-the-art dosimeter [6-7]. As a matter of fact, conventional wired electronics dosimeters (silicon diodes or field effect transistors) allow measuring nuclear dose values only up to few ten of kGy while passive dosimeters (e.g., photo-luminescence, thermo-luminescence or hydrogen pressure dosimeters) require the post-treatment of measurement data [8-9]. In this communication, we report the very first experimental results on an original wireless, chipless and passive (battery-less) sensor for monitoring high doses of nuclear radiation.

\section{SENSOR DESCRIPTION}

The working principle of the proposed sensor is based on the dehydrogenation of polymer material under nuclear irradiation [6-7]. This irradiation generates the outgazing of the polymer placed inside a hermetic micro-cavity (see Figure 1). The resulting overpressure leads to the deflection of a silicon membrane which modifies the resonant frequency of a microwave or millimeter-wave resonator. From the tracking of the resonant frequency the variation of the radiation doses can be derived. The technological process for manufacturing such Hydrogen-Pressure Dosimeters (HPD) is described in [6]. It uses one silicon wafer anodically bonded between two glass wafers for fabricating the micro-cavity and the microwave resonator. The micro-cavity is partially filled with polyethylene and the pressure of nitrogen inside the cavity is around 500 mbar. For illustration purpose the fabricated sensor is shown on Figure 2. The thickness of the silicon membrane is here of $50 \mu \mathrm{m}$.

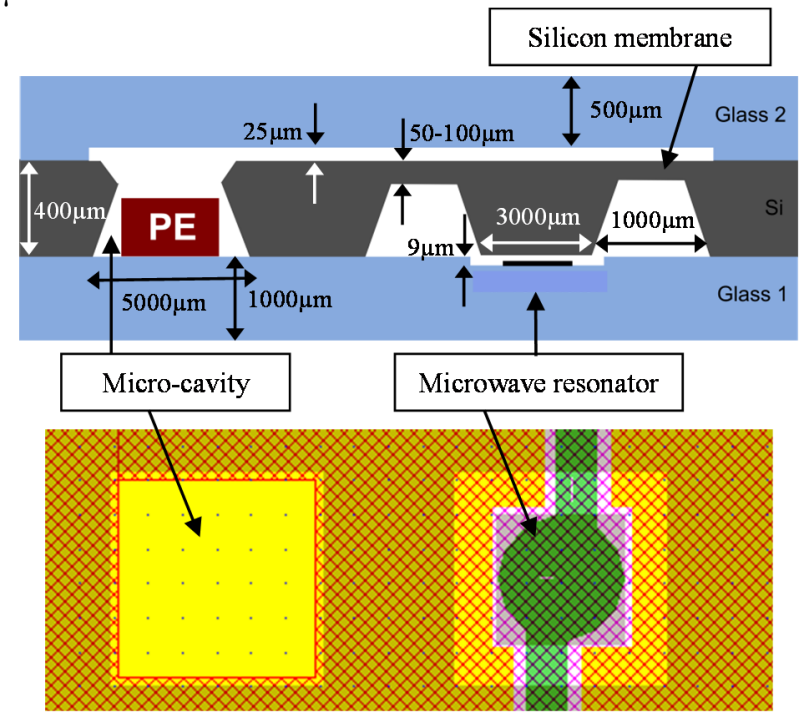

Figure 1 : Cross section and mask view (glass $1 \&$ Si) of the sensor. The acronym PE stands for PolyEthylene 

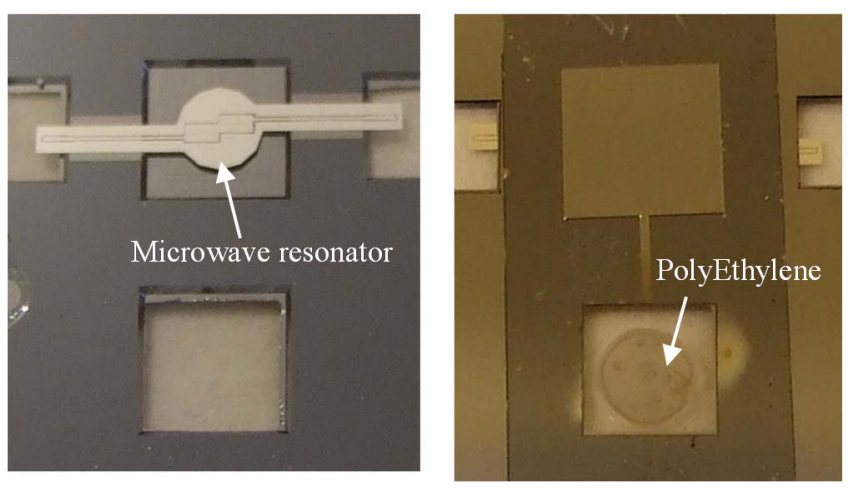

Figure 2: The fabricated sensor (top views). Back side view before HDPE filling \& Glass 2 bonding (left) and top side view after HDPE filling \& Glass 2 bonding (right)

\section{Pressure Measurements}

Before nuclear irradiation the pressure sensor has been calibrated through the measurement of the $\mathrm{S}_{11}$-parameter using Suss-MicroTec MPC-150 chamber for vacuum and atmospheric pressure conditions (see Figure 3). The resonant frequency shift provided by various sensors when a pressure of 1 bar is applied on the silicon membrane is reported in Table 1. The sensitivities ranges from $-5.9 \%$ per bar to $-3.6 \%$ per bar. The accuracy on the resonant frequency measurement is found to $\mathrm{be} \pm 40 \mathrm{MHz}$ (or $\pm 0.15 \%$ ) at $26 \mathrm{GHz}$.

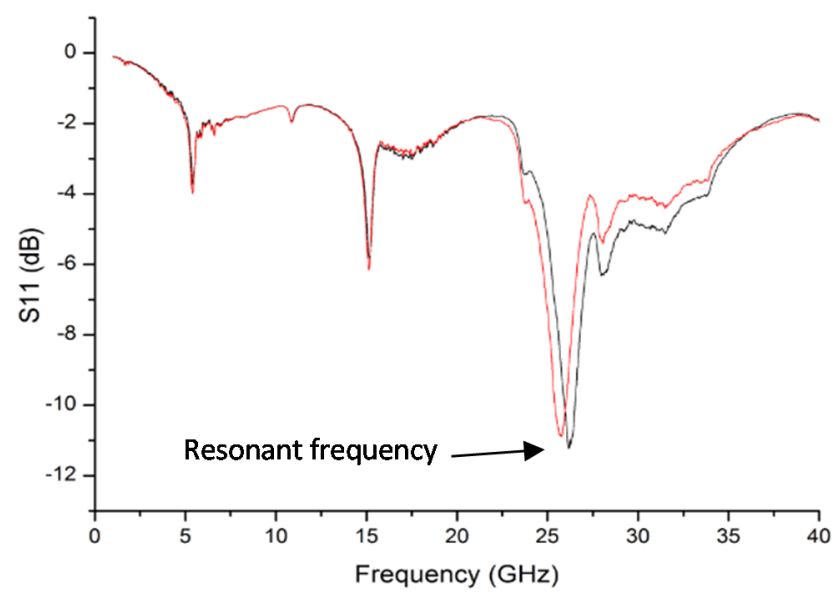

Figure 3: Measured $S_{11}$-parameter versus frequency for atmospheric (in black, 1 bar) and vacuum (in red) pressure conditions.

\begin{tabular}{|c|c|c|c|c|}
\hline & $\begin{array}{c}\text { Sensor } \\
\text { N21-1 }\end{array}$ & $\begin{array}{c}\text { Sensor } \\
\text { N21-2 }\end{array}$ & $\begin{array}{c}\text { Sensor } \\
\text { N21-6 }\end{array}$ & $\begin{array}{c}\text { Sensors } \\
\text { N21-9 }\end{array}$ \\
\hline Freq. shift & $-3.6 \%$ & $-4.6 \%$ & $-5.9 \%$ & $-5.9 \%$ \\
\hline
\end{tabular}

Table 1: Measured resonant frequency difference (in \%) between atmospheric (1 bar) and vacuum pressure conditions.

The hermetic seal of the micro-cavity has been checked from the measurement of the sensor resonant frequency after two days in vacuum pressure condition. A good seal is required as the eventual nitrogen leak by the micro-cavity causes the decrease of the differential pressure applied on the silicon membrane, increases the membrane-to-resonator distance and results in the undesirable variation of the resonant frequency with time. The results shown in Table 2 indicates that the resonant frequency does not significantly change after 47 hours and consequently a good hermetic seal was achieved during the manufacturing process of the sensors' micro-cavities.

\begin{tabular}{|c|c|c|c|c|}
\hline & Sensor & Sensor & Sensor & Sensor \\
& N21-1 & N21-2 & N21-6 & N21-9 \\
\hline Freq. shift & $0.08 \%$ & $0.21 \%$ & $0.09 \%$ & $-0.02 \%$ \\
\hline
\end{tabular}

Table 2 : Measured resonant frequency variation (in \%) for 4 fabricated sensors after 47 hours with vacuum pressure condition.

\section{MeAsured Performances of THE Hydrogen- PRESSURE DOSIMETERS}

The Hydrogen-Pressure Dosimeters have been irradiated using $6 \mathrm{MeV}$ focused e-beam providing by electron accelerator with doses of $20 \mathrm{kGy}$. The obtained resonant frequency shift is reported on Table 3 for various sensors. The measurement sensitivities ranges from $-0.42 \%$ per kGy to $-0.12 \%$ per $\mathrm{kGy}$.

\begin{tabular}{|l|l|l|l|l|}
\hline & Sensor & Sensor & Sensor & Sensor \\
& N21-1 & N21-2 & N21-6 & N21-9 \\
\hline Freq. shift & $-3 \%$ & $-8.4 \%$ & $-2.5 \%$ & $-5.1 \%$ \\
\hline
\end{tabular}

Table 3 : Measured resonant frequency shift (in \%) after e-beam irradiation (20kGy)

The pressure inside the micro-chamber resulting from the outgazing of the polyethylene can be derived from Table 1 and Table 3. The results are reported in Table 4. The sensitivities are between $20 \mathrm{mbar} / \mathrm{kGy}$ and $90 \mathrm{mbar} / \mathrm{kGy}$. These encouraging results are consistent with those obtained in [6] (50mbar/kGy) using specific test structures based on silicon membrane deflection.

\begin{tabular}{|c|c|c|c|c|}
\hline & $\begin{array}{c}\text { Sensor } \\
\text { N21-1 }\end{array}$ & $\begin{array}{c}\text { Sensor } \\
\text { N21-2 }\end{array}$ & $\begin{array}{c}\text { Sensor } \\
\text { N21-6 }\end{array}$ & $\begin{array}{c}\text { Sensor } \\
\text { N21-9 }\end{array}$ \\
\hline $\begin{array}{c}\text { Pressure in the } \\
\text { micro-cavity }\end{array}$ & 0.8 bar & 1.8 bar & 0.4 bar & 0.8 bar \\
\hline
\end{tabular}

Table 4 : Pressure inside the micro-cavity after e-beam irradiation (20kGy). These results are derived from results reported in Tables 1 and 3

In order to check that the seal of the micro-cavity is hermetic to hydrogen, the resonant frequency of sensors has been measured during several months after e-beam irradiation (Figure 4). After few days the frequency shift is found to be very small (no more than $\pm 0.15 \%$ ) and consequently, the sensors sensitivities reported in Table 3 are still applicable. 


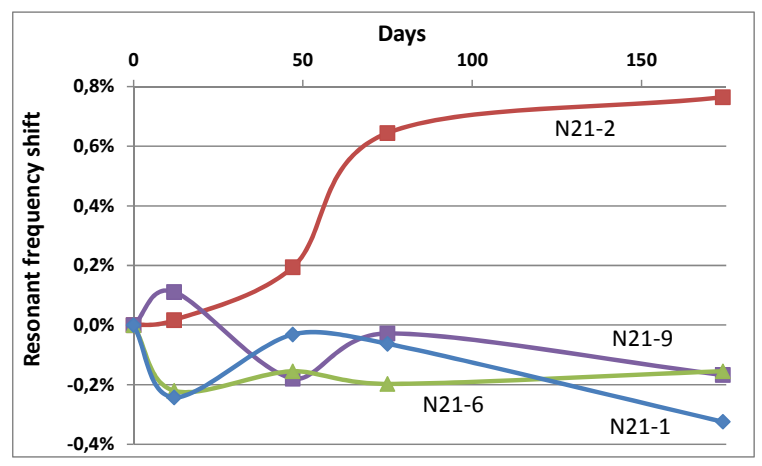

Figure 4 : Measured resonant frequency shift (in \%) versus time after e-beam irradiation for 4 sensors

From Figure 4 it can be observed that the undesirable frequency shift is small after six months for 3 sensors (Sensors N21-1, N21-6 \& N21-9). This results demonstrates that a good longterm hermetic seal was achieved during the manufacturing process of the micro-cavities.

\section{CONCLUSIONS}

For the first time, high dose nuclear radiation dosimeters with wireless capabilities are presented. The sensor is composed of a miniature hydrogen pressure dosimeter and a passive microwave transducer. The good hermetic seal of the constitutive micro-cavities is crucial and is achieved 6 months after nuclear irradiation. The irradiation sensitivity of proposed sensors is measured for $20 \mathrm{kGy}$ e-beam dose and the pressure generated by the hydrogen outgazing inside the sensors' microcavity can be derived.

A large range of pressure is achieved by the proposed sensors. The observed dispersion in the sensors' performances are probably due (1) to the lack of reproducibility in the hydrogen outgazing of the polyethylene which was used in this first experiment and, (2) to the complex mechanical behavior of non-conventional bossed silicon membrane.

Research are now focused on design optimization and reliability studies of the three transducers used in the sensor (hydrogen outgazing, bossed membrane, microwave resonator)

\section{ACKNOWLEDGEMENTS}

This work was performed in the framework of FP7-MNTERA.NET-DOSIMEMS project funded by EU via Foundation for Polish Science and by Midi-Pyrénées Region and was partly supported by LAAS-CNRS micro and nano-technologies platform, member of the French RENATECH network. The authors want also to thank the European Commission for financial support through the H2020-ICT Project GateOne.

\section{REFERENCES}

[1] T.Thai, M.-M.Jatlaoui, F.Chebila, H.Aubert, P.Pons, G.-R.DeJean, M.M. Tentzeris, R.Plana, "Design and Development of a Novel Passive Wireless Ultrasensitive RF Temperature Transducer for Remote Sensing," IEEE Sensors Journal, Vol. 12, Issue 9, pp. 2756-2766, September 2012.

[2] T. T. Thai, M. Jatlaoui, H. Aubert, P. Pons, G. R. DeJean, M. M. Tentzeris, R. Plana, "A Novel Passive Wireless Ultrasensitive RF Temperature Transducer for Remote Sensing," IEEE International Microwave Symposium, Anaheim, California, USA, pp. 473-476, 23-28 May 2010

[3] T.Thai, H.Aubert, P.Pons, G.DeJean, M.- M.Tentzeris, R.Plana, "Novel Design of a Highly Sensitive RF Strain Transducer for Passive and Remote Sensing in Two Dimensions," IEEE Transactions on Microwaves Theory and Techniques, Vol. 61, Issue 3, pp. 1385-1396, March 2013.

[4] S.Bouaziz, F.Chebila, A.Traille, P. Pons, H. Aubert, M.-M. Tentzeris, "Novel Micro-fluidic Structures for Wireless Passive Temperature Telemetry Medical Systems Using Radar, Interrogation Techniques in Ka-band," IEEE Antennas and Wireless Propagation Letters, vol. 11, pp. $1706-1709,2012$.

[5] M. Jatlaoui, F. Chebila, P. Pons, H. Aubert, "Working Principle Description of the Wireless Passive EM Transduction Pressure Sensor", European Physical Journal - Applied Physics, Vol 56, Nº1, oct 2011

[6] E Debourg, A Rifai, I. Augustyniak, M. Matusiak ,M.Olszacki, P. Knapkiewicz, J. Dziuban, H. Aubert, P.Pons, "High doses wireless radiation sensor using electromagnetic transducers, "European Microwave Week, 6-11 Sept 2015, Paris, France

[7] I. Augustyniak, P. Knapkiewicz, K. Sareło, J. A. Dziuban, E. Debourg, M. Olszacki, P. Pons, "Micromechanical high-doses radiation sensor with bossed membrane and interferometry optical detection", Sensors and Actuators, Volume 232, 1 August 2015, Pages 353-358

[8] K. Brabcová, I. Jadrnícková, A.G. Molokanov, et al., Dosimetry in heavy ion beams using various detectors, Radiat. Meas. 45 (2010) 1384-1386.

[9] J. Barthe, Electronic dosimeters based on solid state detectors, Nucl. Instrum. Methods Phys. Res. B 184 (2001) 158-189. 